\title{
AVALIAÇÃO REOLÓGICA E SENSORIAL DE GELÉIAS COM BAIXO TEOR DE SÓLIDOS SOLÚVEIS COM DIFERENTES HIDROCOLÓIDES OBTIDAS A PARTIR DE FORMULAÇÕES EM PÓ
}

\author{
SIMONE MARIA RIBAS VENDRAMEL * \\ LYS MARY BILESKI CÂNDIDO ** \\ ADRIANE MULINARI CAMPOS ***
}

\begin{abstract}
Desenvolveu-se formulações em pó para o preparo doméstico de geléias destinadas para diabéticos, modificadas em seu teor de carboidratos, com diferentes hidrocolóides e substitutos de açúcar. Foram testados 22 diferentes hidrocolóides e 6 edulcorantes. Géis modelo obtidos a partir de pectinas, gomas, ou associações de ambas foram previamente avaliados reologicamente, quanto a fluidez, viscosidade e força de gel, visando identificar as associações com melhores características. Dezesseis géis foram selecionados e a partir destes desenvolveu-se formulações em pó para preparo de geléia, as quais foram testadas com abacaxi, morango, manga, pêssego e maçã. Determinou-se o teor de cálcio livre das frutas por espectrometria de absorção atômica. As geléias preparadas em batelada, de modo a apresentarem no final $55 \%$ de fruta e 25 a $30 \%$ de sólidos solúveis, foram submetidas às mesmas avaliações reológicas dos géis. Avaliou-se sensorialmente as geléias adoçadas com aspartame através da escala hedônica de sabor. O preparo doméstico de geléias, a partir das formulações em pó desenvolvidas, foi avaliado por voluntários da Associação do Diabético Carente do Paraná. Os valores de fluidez, viscosidade e força do gel demonstraram que a utilização de hidrocolóides isolados ou associados, ao invés de pectina BTM, utilizada isoladamente pela maioria das indústrias, permite implementação das propriedades reológicas. Foram confirmadas a viabilidade do preparo de geléias a partir de formulações em pó, bem como a boa qualidade do produto quanto ao sabor, aparência e textura.
\end{abstract}

* Aluna do Curso de Engenharia Química da Pontifícia Universidade Católica do Paraná (PUC-PR).

** Professora da Disciplina de Bioquímica de Alimentos do Departamento de Nutrição da Universidade Federal do Paraná (UFPR).

*** Professora da Disciplina de Química Tecnológica do Departamento de Engenharia Química da PUC-PR. 
Considerando o alto custo dos alimentos para fins comerciais especiais, principalmente os destinados para diabéticos ( $7 \%$ da população), bem como a crescente demanda por alimentos com baixas calorias, têm sido desenvolvidas formulações em pó para preparo rápido de geléias com baixo teor de sólidos solúveis, para diabéticos, obesos ou consumidores por opção. Estas geléias podem ser preparadas pelo próprio usuário com a fruta desejada, obtendo produto com custo muito inferior aos encontrados comercialmente e de alta qualidade (4).

As geléias com baixo teor de sólidos solúveis, destinadas à dietas de restrição calórica ou para diabéticos, são comumente formuladas através do uso de pectinas baixo teor de metoxilação (BTM) (1). Tais pectinas formam gel em presença de íons metálicos bivalentes, normalmente cálcio, não necessitando da presença de açúcares.

A utilização de pectinas BTM e a substituição de açúcar podem ocasionar sinérese, textura frágil, falta de limpidez, perda de coloração e de sabor, além de aumentar o risco de contaminação por fungos e leveduras, diminuindo a vida-de-prateleira das geléias $(1,2,3)$.

Outros hidrocolóides têm sido incluídos na elaboração destas geléias com o objetivo de se obter melhores características reológicas e evitar sinérese. Vários autores sugerem 0 uso de: carragenas $(6,8,11,17)$, carboximetilcelulose $(9,15)$, goma xantana $(7,10)$, gomas guar $(5,8)$ e jataí $(5,10)$, gelana $(8,9,11,14,18,19,21)$, alginato de sódio (15) e outros $(20,22)$.

Para otimizar "formulações em pó para preparo rápido de geléias" com baixo teor de sólidos solúveis, obtidas em trabalho anterior $(1,2,3)$, utilizando pectina BTM amidada como agente geleificante, testou-se outros hidrocolóides, isolados ou em associação. Estes foram previamente avaliados reologicamente na forma de gel modelo e posteriormente na forma de geléias com diferentes frutas, adoçantes e edulcorantes.

\section{MATERIAL E MÉTODOS}

\subsection{MATERIAL}

No preparo dos géis modelo e das geléias utilizou-se os edulcorantes e hidrocolóides apresentados nos Quadros 1 e 2, respectivamente.

Utilizou-se também frutas da época: abacaxi (Hawai), morango (Sequóia), manga (Háden), pêssego (Flor da Prince) e maçã (Fuji), assim como os aditivos cloreto de cálcio dihidratado, sorbato de potássio, benzoato de sódio e ácido cítrico monohidratado. 


\section{QUADRO 1 - EDULCORANTES EMPREGADOS NA ELABORAÇÃO DAS GELÉIAS}

\begin{tabular}{|l|c|c|}
\hline EDULCORANTES & FABRICANTES & COMPOSIÇÃO \\
\hline Sorbitol & Getec Guanabara Química Industrial & $\begin{array}{c}98,40 \% \text { de sorbitol } \\
0,67 \% \text { de manitol } \\
0,19 \% \text { de umidade }\end{array}$ \\
\hline Aspartame & HSC Holand Sweetener Company & \\
\hline Sacarina sódica & Panamericana S.A. Indústrias & $99,40 \%$ base anidra \\
Químicas & $13,75 \%$ de umidade \\
\hline Ciclamato de sódio & Brasfanta Indústria e Comércio & \\
& Ltda. & \\
\hline Acesulfame-K & Hoechst do Brasil Química e & \\
& Farmacêutica S.A & $80 \%$ esteviosídio \\
Esteviosídeo & Ingá Stevia Industrial S.A & $19 \pm 1 \%$ rebaudiosídeo \\
& & $\mathrm{A}<1 \%$ rebaudiosídeo C \\
\hline Alitame & Cultor Food Science & \\
\hline
\end{tabular}

\section{QUADRO 2 - HIDROCOLÓIDES EMPREGADOS NA ELABORAÇÃO DOS GÉIS MODELO E DAS GELÉIAS}

\begin{tabular}{|l|l|}
\hline \multicolumn{1}{|c|}{ HIDROCOLÓIDES } & \multicolumn{1}{c|}{ FABRICANTES } \\
\hline Alginato de sódio & $\begin{array}{l}\text { Grinsted do Brasil Indústria e Com. Ltda. } \\
\text { Systems Bio-Industries (SBI) }\end{array}$ \\
\hline Carboximetilcelulose & Aqualon \\
\hline Amido modificado (Cleargel) & National Starch \& Chemical Industrial Ltda. \\
\hline Goma carragena & $\begin{array}{l}\text { Systems Bio-Industries (SBI) } \\
\text { Copenhagen Pectin (Hercules) } \\
\text { Grinsted do Brasil Indústria e Com. Ltda. }\end{array}$ \\
\hline Goma guar & $\begin{array}{l}\text { Sigma } \\
\text { FMC Corporation }\end{array}$ \\
\hline Gelcarin & FMC Corporation \\
\hline Goma gelana & Kelco of Merck \& Co. Inc. \\
\hline Goma jataí (LBG) & $\begin{array}{l}\text { Systems Bio-Industries (SBI) } \\
\text { Grinsted do Brasil Indústria e Com. Ltda. }\end{array}$ \\
\hline Polidextrose (Litesse) & Cultor Food Science \\
\hline $\begin{array}{l}\text { Celulose } \\
\text { (Methocel) }\end{array}$ & The Dow Chemical Company \\
\hline Pectina amidada & $\begin{array}{l}\text { Braspectina S.A. } \\
\text { Grinsted do Brasil Indústria e Com. Ltda. } \\
\text { Copenhagen Pectin (Hercules) }\end{array}$ \\
\hline Goma xantana & $\begin{array}{l}\text { Rhodia. Grupo Rhône - Poulenc } \\
\text { Systems Bio-Industries (SBI) }\end{array}$ \\
\hline & \\
\hline
\end{tabular}




\subsection{MÉTODOS}

\subsubsection{Preparo e avaliação reológica dos géis modelo}

Preparou-se todas as soluções de hidrocolóides em água quente (em torno de $80^{\circ} \mathrm{C}$ ) mediante intensa agitação, embora alguns hidrocolóides como alginato (15), goma xantana (5), jataí (5), guar $(5,6,10)$ e CMC $(15,16)$ possam ser preparados em água fria.

Para estudo do comportamento reológico dos diferentes hidrocolóides, testados isolados e em associação, foram elaborados géis modelo, de maneira que apresentassem $\mathrm{pH}$ e teor de sólidos solúveis próximos dos das geléias a serem desenvolvidas (aproximadamente 25\% de sólidos solúveis), utilizando sorbitol (4) como agente de corpo e pH na faixa de 3,2 a 3,5, ajustado com solução de ácido cítrico monohidratado.

O teor de cálcio $(2,3)$, indispensável para geleificação de quase todos os hidrocolóides, foi ajustado com soluções de cloreto de cálcio, dentro de faixas determinadas pela literatura para cada hidrocolóide $(5,8,9,10,12,14,20)$.

Preparou-se os géis com água deionizada, de acordo com as restrições para dissolução de cada hidrocolóide, assim como suas associações. Tais restrições referem-se principalmente a temperatura da água e grau de agitação.

Os géis foram embalados em recipientes de $100 \mathrm{~mL}$ com tampa e acondicionados sob refrigeração a $2^{\circ} \mathrm{C}$. Após 10 dias de preparo determinou-se as seguintes características reológicas a temperatura ambiente: força do gel (medida da profundidade de penetração do cone após 15 segundos) em penetrômetro Universal (13), fluidez (extensão que o produto ocupa após fluir por 5 minutos) através de consistômetro (13), e viscosidade (resistência a deformação após 10 minutos) em viscosímetro de Brookfield (13). A partir destes resultados selecionou-se os melhores géis para confecção das geléias.

\subsubsection{Avaliação físico-química das frutas}

$\mathrm{O} \mathrm{pH}$ das frutas foi determinado potenciometricamente através de pHmetro Micronal e os sólidos solúveis através de refratômetro de campo Atago.

O teor de cálcio total da fruta foi avaliado volumetricamente e o teor de cálcio livre da fruta, de vital importância para o grau de geleificação, através de espectrometria de absorção atômica, fazendo-se pré-tratamento 
das amostras conforme propõe o Manual da Indústria de Processamento de Frutas (13). Todas as análises foram feitas a temperatura ambiente.

\subsubsection{Preparo das geléias através da adequação dos resultados dos géis modelo}

Antes da obtenção das formulações em pó elaborou-se várias geléias com o objetivo de testar os géis modelo. As geléias foram preparadas em batelada e em recipiente aberto de aço inox, totalizando $500 \mathrm{~g}$ de geléia para teste de cada uma das 16 formulações selecionadas. Cada geléia obtida foi separada em 5 recipientes plásticos com tampa para armazenagem em geladeira. Estas diferenciavam-se pelo edulcorante adicionado, ou seja, aspartame, acesulfame-K, esteviosídeo, alitame e ciclamato/sacarina $(1,2,3,4)$.

Para adição dos ingredientes considerou-se as variações na composição química das frutas (1), como $\mathrm{pH}$, sólidos solúveis e cálcio livre, procedendo-se os ajustes nescessários. Os teores de cálcio, de ácido cítrico e dos hidrocolóides a serem adicionados foram determinados de acordo com os resultados obtidos com os géis modelos. Calculou-se as quantidades de adoçantes e edulcorantes a serem adicionados às geléias de maneira que todas as geléias apresentassem 25 a 30\% de sólidos solúveis e doçura equivalente a geléia com $30 \%$ de sacarose. Para ajuste da doçura das geléias, adotou-se os poderes adoçantes para os substitutos de açúcar apresentados por CÂNDIDO \& CAMPOS (4) ou conforme estipulado pelos fabricantes. O sorbitol foi utilizado como agente de corpo, tendo-se levado em consideração seu poder edulcorante.

Elaborou-se geléias de abacaxi, morango, manga, pêssego e maçã, as quais foram avaliadas reologicamente (fluidez, viscosidade e força do gel).

\subsubsection{Avaliação sensorial das geléias}

Cinco grupos de 10 pessoas representadas por alunos dos cursos de Farmácia, Engenharia Química, Engenharia de Alimentos e funcionários da Usina Piloto da PUC-PR, que se declararam consumidores de geléia, apresentaram interesse e disponibilidade para os testes. Entre os julgadores, a faixa etária variou de 19 a 35 anos de idade, sendo 30 do sexo masculino e 20 do sexo feminino. Cada grupo de 10 pessoas avaliou um sabor de geléia. Esta etapa de avaliação sensorial teve como objetivo selecionar as geléias com melhores características de sabor. As geléias selecionadas foram avaliadas pelos atributos de aparência, aroma, cor característica, nível de doçura, nível de acidez e consistência, através de Análise Quantitativa Descritiva (ADQ). 
Para realização dos testes acomodou-se os julgadores em cabines individuais com iluminação fluorescente natural, nos períodos das 9h30min às $11 \mathrm{~h}$ da manhã e das $15 \mathrm{~h} 30 \mathrm{~min}$ às $17 \mathrm{~h}$ da tarde. As geléias avaliadas sensorialmente foram as mesmas avaliadas reologicamente.

Amostras de aproximadamente 5 gramas foram apresentadas a temperatura ambiente, de forma aleatória em copos plásticos de $50 \mathrm{~mL}$, sempre acompanhadas de água e biscoito água e sal. Orientou-se os julgadores para avaliarem somente o sabor das geléias. Utilizou-se a escala hedônica de seis pontos (no máximo 6 amostras), sendo o ponto um representativo de excelente e o ponto seis de péssimo (Figura 1).

\section{FIGURA 1 - FICHA REPRESENTATIVA DA ANÁLISE SENSORIAL}

Avalie o sabor de cada amostra, indicando sua opinião com um X na escala abaixo:

\begin{tabular}{|l|l|l|l|l|l|l|}
\cline { 2 - 7 } \multicolumn{1}{c|}{} & \multicolumn{7}{c|}{ AMOSTRAS } \\
\hline & 1 & 2 & 3 & 4 & 5 & 6 \\
\hline excelente & & & & & & \\
\hline ótimo & & & & & & \\
\hline bom & & & & & & \\
\hline médio & & & & & & \\
\hline ruim & & & & & & \\
\hline péssimo & & & & & & \\
\hline
\end{tabular}

Em função do elevado número de amostras a serem avaliadas, (16 de abacaxi, 16 de morango, 14 de manga, 9 de pêssego e 3 de maçã para 5 edulcorantes diferentes) totalizando 290 amostras e levando-se em consideração que o presente trabalho enfatiza o estudo dos hidrocolóides, optou-se por realizar análise sensorial apenas dos produtos adicionados de aspartame $(1,2,3,4)$. Este apresenta o perfil de doçura que mais se aproxima da sacarose, não deixando qualquer gosto residual amargo, químico ou metálico, freqüentemente associado a outros edulcorantes $(1,2,3,4)$. Avaliou-se o sabor das geléias de abacaxi, morango e manga em três sessões, as de pêssego em duas sessões e as de maçã em apenas uma sessão. Julgou-se no máximo 6 amostras por sessão, minimizando a fadiga que poderia diminuir a habilidade para distinguir o sabor das amostras. A duração das avaliações e o intervalo entre as mesmas ficaram 
inteiramente a critério dos julgadores, tendo sido respeitada a velocidade individual de julgamento de todos.

Os valores obtidos no teste de preferência foram submetidos a análise de variância, seguida do cálculo das diferenças mínimas significativas (DMS ou Teste de Bonferroni) para ordenação das médias. As determinações foram efetuadas pelo programa estatístico de computador True Epistat.

\subsubsection{Teste e preparo das formulações em pó}

Ajustou-se o preparo das formulações em pó mantendo os ingredientes e aditivos no estado sólido, com exceção da fruta, através da média de teores dos componentes utilizados para confeccionar as geléias de cada fruta. Testes para verificação da solubilidade dos componentes da formulação foram efetuados de modo que se obtivesse solubilização mais eficaz e prática possível.

Testou-se a viabilidade destas formulações com morango para cada um dos 16 géis modelo selecionados anteriormente, sendo que as geléias confeccionadas a partir destas formulações também tiveram suas características reológicas avaliadas.

Treze pessoas da Associação do Diabético Carente do Paraná demonstraram disponibilidade e interesse em testar a praticidade e características organolépticas das formulações em pó. Cada participante recebeu duas amostras de diferentes formulações para preparo rápido de geléias, juntamente com uma ficha de avaliação, referente a praticidade de preparo do produto, sua aceitação no mercado e sabor. Estabeleceu-se o prazo de 15 dias para a devolução das fichas, sendo sugerida a utilização de morango para o preparo das geléias.

\section{RESULTADOS E DISCUSSÃO}

\subsection{PREPARO E AVALIAÇÃO REOLÓGICA DOS GÉIS MODELO}

O Quadro 3 apresenta os resultados da determinação de $\mathrm{pH}$ dos ingredientes comerciais. Estes dados serviram como base para a padronização da quantidade de solução de ácido cítrico monohidratado necessária para o ajuste do $\mathrm{pH}$ dos géis modelo e das geléias, compensando-se posteriormente a alteração causada pela adição da fruta. O Quadro 3 também apresenta dados relativos à avaliação visual da cor das matérias-primas.

A Figura 2 apresenta os dados obtidos para fluidez, viscosidade e força do gel, para os géis modelo. Alguns hidrocolóides, apesar de apresentarem valores satisfatórios de viscosidade, não geleificaram, entretanto, 
alcançaram bons resultados em associação com outros hidrocolóides, como por exemplo goma guar $(5,20)$ e jataí $(5,20)$. Os números na abcissa representam os hidrocolóides que foram utilizados, como descrito abaixo do gráfico.

Pelos valores de viscosidade e fluidez observou-se que os géis dos hidrocolóides associados geraram sinergismo. Os géis com valores de fluidez na faixa de 20 a $36 \mathrm{~mm}$ e viscosidade acima de $8.000 \mathrm{cps}$ foram os que apresentaram melhores características de consistência. Os valores de força de gel demonstraram características semelhantes na faixa de variação entre 180 e $220 \mathrm{~mm}$.

\section{QUADRO 3 - CARACTERIZAÇÃO DOS HIDROCOLÓIDES}

\begin{tabular}{|c|c|c|c|}
\hline HIDROCOLÓIDES & FABRICANTES & $\mathbf{p H}$ & COLORAÇÃO \\
\hline \multirow[t]{2}{*}{ Alginato de sódio } & Grinsted do Brasil Indústria e Com. Ltda. & 7,2 & clara \\
\hline & Systems Bio-Industries & 7,4 & amarela \\
\hline Carboximetilcelulose & Aqualon & 7,5 & branca \\
\hline Cleargel & National Starch & 5,3 & branca \\
\hline \multirow[t]{3}{*}{ Carragena } & Systems Bio-Industries & 7,0 & clara \\
\hline & Copenhagen Pectin (Hercules) & 7,0 & amarela clara \\
\hline & Grinsted do Brasil Indústria e Com. Ltda. & 9,0 & opaca \\
\hline \multirow[t]{2}{*}{ Goma guar } & Sigma & 5,8 & opaca \\
\hline & FMC Corporation & 6,5 & opaca \\
\hline Gelcarin & FMC Corporation & 7,5 & opaca \\
\hline Gelana & Kelco of Merck \& Co. Inc. & 7,5 & transparente \\
\hline \multirow[t]{2}{*}{ Goma jataí (LBG) } & Systems Bio-Industries & 6,3 & opaca \\
\hline & Grinsted do Brasil Indústria e Com. Ltda. & 5,5 & opaca \\
\hline Litesse & Cultor Food Science & 5,3 & transparente \\
\hline Methocel & The Dow Chemical Company & 7,5 & clara \\
\hline \multirow[t]{4}{*}{ Pectina amidada } & Braspectina S.A. - BTM 8001 & 4,7 & amarela \\
\hline & - BTM 8002 & 4,2 & amarela \\
\hline & Grinsted do Brasil Indústria e Com. Ltda. & 4,3 & clara \\
\hline & Copenhagen Pectin (Hercules) & 4,5 & clara \\
\hline \multirow[t]{2}{*}{ Xantana } & Rhodia S.A. & 6,0 & opaca \\
\hline & Systems Bio-Industries & 5,9 & opaca \\
\hline
\end{tabular}


FIGURA 2 - FLUIDEZ, VISCOSIDADE E FORÇA DOS GÉIS MODELO
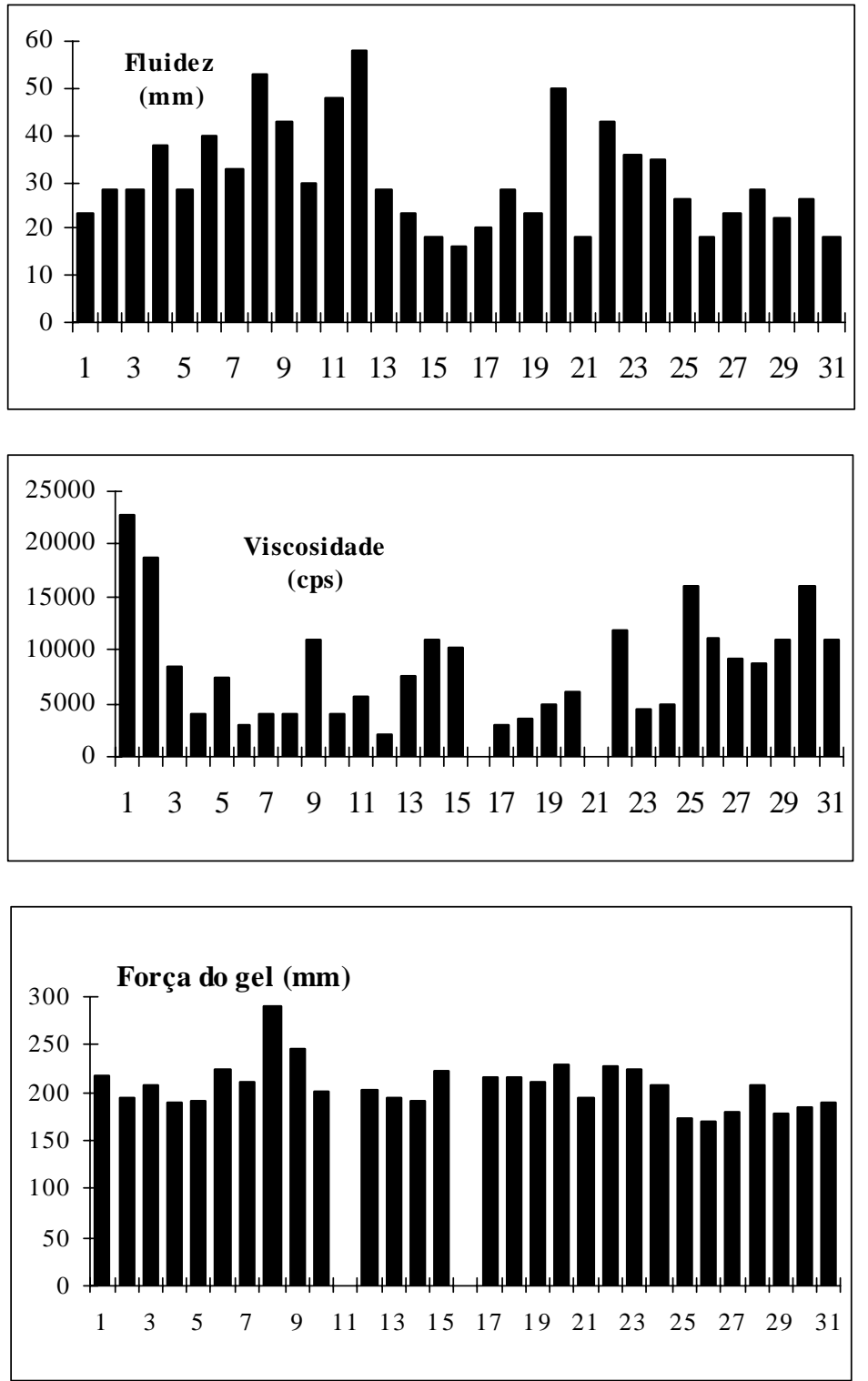

Alginato (SBI)

Alginato (Grinsted)

Carragena (SBI)

Carragena (Grinsted)

Carragena (Genu)

Cleargel (National)

Gelana (Kelco)

Guar (Sigma)

Guar (Edicol)

Gelcarin (FMC Corporation)

Goma jataí (SBI)

Goma jataí (Grinsted)

Goma xantana (SBI)

Goma xantana (Rhodia)

Pectina (Grinsted)

Pectina 8.001 (Braspectina)
Pectina 8.002 (Braspectina)

Pectina 8.003 (Braspectina)

Pectina (Copenhagen)

CMC (Aqualon)

Cleargel (National) / Methocel (Dow)

CMC (Aqualon) / Goma Guar (FMC Corp.)

Pectina (Copenhagen) / Carragena (SBI)

Pectina (Copenhagen) / Goma xantana (SBI)

Pectina (Copenhagen) / Goma Jataí (SBI)

Pectina (Copenhagen) / Agar

Gelana (Kelco) / Goma Guar (FMC Corp.)

Gelana (Kelco) / Carragena (SBI)

Gelana (Kelco) / Goma xantana (SBI)

Goma xantana (SBI) / Goma Jataí (SBI)

Carragena (SBI) / Goma Jataí (SBI) 
A faixa de concentração de hidrocolóides situou-se entre 0,7 e 1,0\%. Seguindo-se o mesmo critério, o teor de cálcio foi ajustado de acordo com o hidrocolóide empregado, sendo que Gelcarin, Cleargel e Methocel (22) e CMC $(15,22)$ não necessitaram de cálcio para geleificação.

$\mathrm{Na}$ escolha dos géis modelo considerou-se os hidrocolóides com melhores características reológicas, ou seja, melhores dados de fluidez, viscosidade e força do gel (Quadro 4), procurando-se trabalhar apenas com um fabricante de cada hidrocolóide.

\section{QUADRO 4 - GÉIS MODELO SELECIONADOS PARA ELABORAÇÃO DAS GELÉIAS}

\begin{tabular}{|c|l|}
\hline $\mathbf{N}^{\mathbf{0}}$ & \multicolumn{1}{|c|}{ HIDROCOLÓIDES } \\
\hline 1 & Alginato de Sódio (SBI) \\
\hline 2 & Carragena (SBI) \\
\hline 3 & Gelana (Kelco) \\
\hline 4 & Gelcarin (FMC Corporation) \\
\hline 5 & Goma xantana (SBI) \\
\hline 6 & Pectina (Copenhagen Pectin) \\
\hline 7 & Pectina (Copenhagen Pectin) \Litesse (Pfizer) \\
\hline 8 & Pectina (Copenhagen Pectin) $\backslash$ Carragena (SBI) \\
\hline 9 & Pectina (Copenhagen Pectin) $\backslash$ Goma xantana (SBI) \\
\hline 10 & Pectina (Copenhagen Pectin) $\backslash$ Goma Jataí (SBI) \\
\hline 11 & Gelana (Kelco) $\backslash$ Goma guar (FMC Corporation) \\
\hline 12 & Gelana (Kelco) \Carragena (SBI) \\
\hline 13 & Gelana (Kelco) $\backslash$ Goma xantana (SBI) \\
\hline 14 & Carragena (SBI) $\backslash$ Goma Jataí (SBI) \\
\hline 15 & Cleargel (National) $\backslash$ Methocel (Dow) \\
\hline 16 & Carboximetilcelulose (Aqualon) \\
\hline & \\
\hline
\end{tabular}

\subsection{AVALIAÇÃO FÍSICO-QUÍMICA DAS FRUTAS}

A Tabela 1 apresenta os resultados da análise físico-química das frutas. 
TABELA 1 - CARACTERÍSTICAS FÍSICO-QUÍMICAS DAS FRUTAS

\begin{tabular}{c|c|c|c|c}
\hline FRUTA & pH & $\begin{array}{c}\text { SÓLIDOS } \\
\text { SOLÚVEIS }\left({ }^{\mathbf{B} B r i x)}\right.\end{array}$ & $\begin{array}{c}\text { TEOR DE CÁLCIO } \\
\text { TOTAL (mg\%) }\end{array}$ & $\begin{array}{c}\text { TEOR DE CÁLCIO } \\
\text { LIVRE (mg \%) }\end{array}$ \\
\hline pêssego & 3,1 & 8,0 & 23,78 & 10,47 \\
\hline morango & 3,5 & 7,8 & 23,77 & 15,31 \\
\hline maçã & 3,6 & 12,4 & 13,17 & 8,86 \\
\hline manga & 3,4 & 11,4 & 15,82 & 14,5 \\
\hline abacaxi & 3,3 & 16,8 & 21,11 & 13,7 \\
\hline
\end{tabular}

Grande parte do cálcio necessário para formar o gel é originário da fruta. A determinação do teor de cálcio livre da fruta é de vital importância durante a formação da rede de gel para a maioria dos hidrocolóides. O teor de cálcio livre $(1,3)$ indica a quantidade de cálcio disponível no meio a ser geleificado após cozimento, ou seja, no término do processo de elaboração de geléia.

Os resultados das determinações de $\mathrm{pH}$ e sólidos solúveis das frutas apresentaram valores próximos aos citados na literatura (1). Os teores de cálcio total obtidos também assemelharam-se aos registrados na literatura (1), exceto para maçã. Para cálcio livre a semelhança foi ainda maior, com exceção do abacaxi.

\subsection{PREPARO DAS GELÉIAS ATRAVÉS DA ADEQUAÇÃO DOS RESULTADOS DOS GÉIS MODELO}

O tempo de cocção ótimo para elaboração das geléias foi de 15 minutos, em fogo baixo e em recipiente pequeno, com temperatura final na faixa de 80 a $90^{\circ} \mathrm{C}$, dependendo do hidrocolóide. Os edulcorantes, adicionados posteriormente, não afetaram as características reológicas das geléias.

As Figuras 3, 4 e 5, cujas legendas encontram-se no Quadro 4, apresentam os resultados da avaliação reológica das geléias de abacaxi, morango, manga, pêssego e maçã.

As características reológicas dos hidrocolóides alteraram-se acentuadamente com a adição da fruta, sendo que os valores de viscosidade e força do gel aumentaram e os valores de fluidez diminuiram em relação aos géis modelo.

Quanto a fluidez das geléias, aquelas contendo maçã e manga foram as que apresentaram menores valores de extensão do produto. As geléias de pêssego obtiveram em média valores mais altos em comparação com 
aqueles observados para as outras frutas, sendo que as geléias de abacaxi e morango não apresentaram o mesmo comportamento (Figura 3).

Em relação a viscosidade, novamente as geléias de maçã e manga foram as que demonstraram maior grau de resistência à deformação. Em média as geléias de pêssego foram as que evidenciaram menor viscosidade em comparação com os outros sabores. As geléias de abacaxi e morango apresentaram valores próximos, com exceção das formulações 11 (gelana/guar), 12 (gelana/carragena), 14 (carragena/jataí) e 16 (carboximetilcelulose) (Figura 4).

\section{FIGURA 3 - FLUIDEZ DAS GELÉIAS}

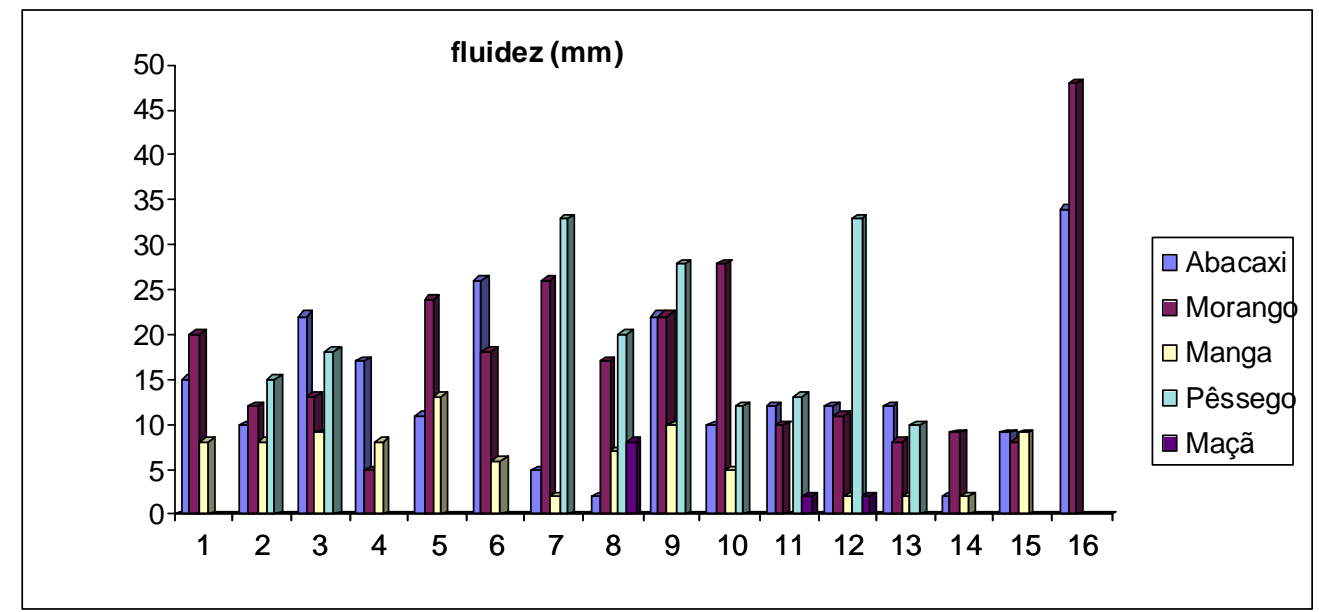

Observou-se que, em média, as geléias de maçã, seguidas das de manga, apresentaram os menores valores de força de gel. As geléias de abacaxi com formulações de associações de gomas evidenciaram em média valores mais altos do que aquelas formuladas com uma das gomas isoladamente. As geléias de morango apresentaram comportamento inverso. A força de gel das geléias de pêssego não variou em função da presença de gomas adicionadas isoladamente ou em associação (Figura 5).

Através da análise dos dados de fluidez, viscosidade e força do gel, observou-se claramente que as geléias de manga e maçã alcançaram maior consistência em relação às outras frutas. Os melhores dados de consistência para as geléias foram observados na faixa de 5 a $17 \mathrm{~mm}$ para fluidez e na faixa de 12.000 a $30.000 \mathrm{cps}$ para viscosidade. Em relação a força do gel, apesar de valores distintos, as formulações apresentaram características semelhantes, exceto a de número 16 (carboximetilcelulose). 
FIGURA 4 - VISCOSIDADE DAS GELÉIAS

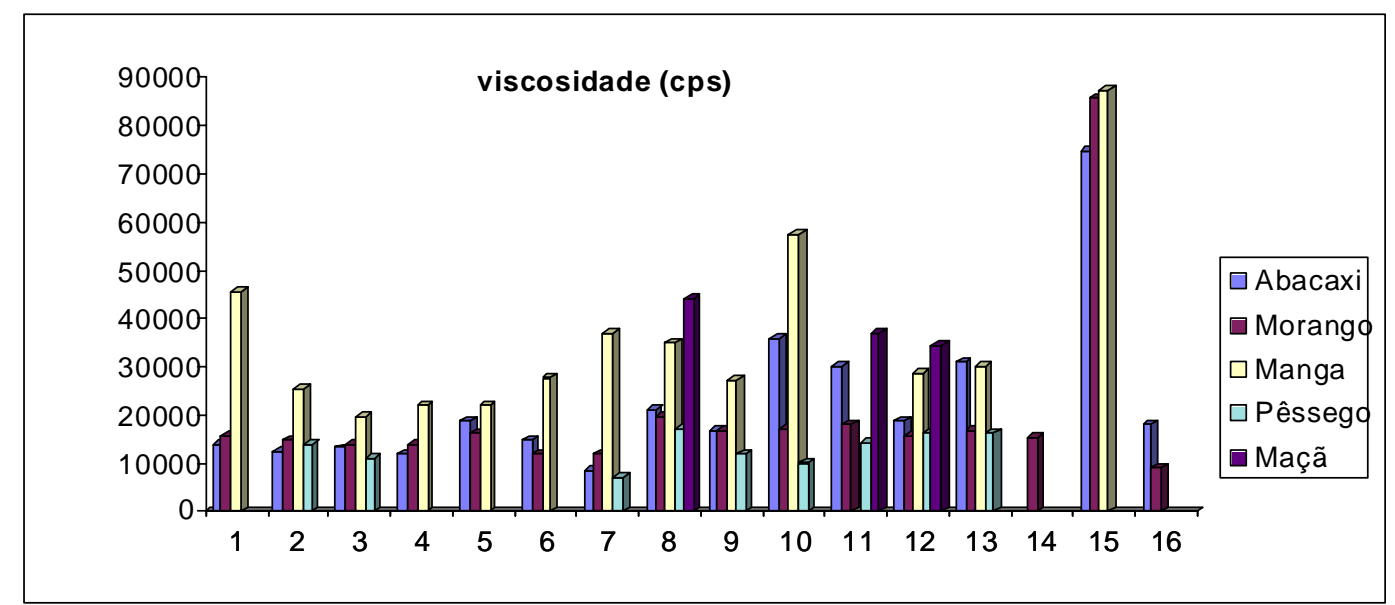

\section{FIGURA 5 - FORÇA DAS GELÉIAS}

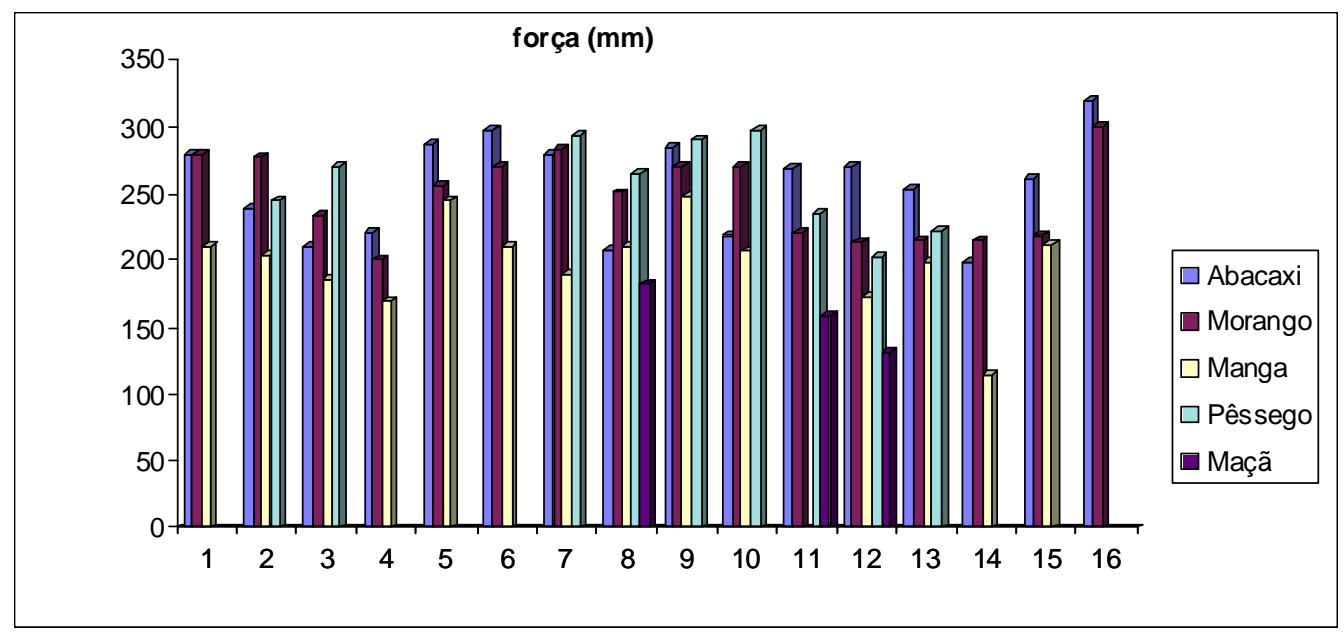

\subsection{AVALIAÇÃO SENSORIAL DAS GELÉIAS}

$\mathrm{Na}$ Tabela 2 são apresentadas as médias dos resultados do teste de preferência de sabor para as geléias de morango, manga, abacaxi, maçã e pêssego, cujos dados podem ser melhor avaliados pelo gráfico da Figura 6.

A geléia de morango com carragena foi considerada a melhor amostra quanto ao sabor, seguida pelas amostras com pectina/polidextrose, pectina/ carragena e alginato, respectivamente. A geléia com carragena apresentou diferença significativa ao nível de $5 \%$ em relação as amostras com gelana/ carragena, Cleargel/Methocel e carboximetilcelulose. 


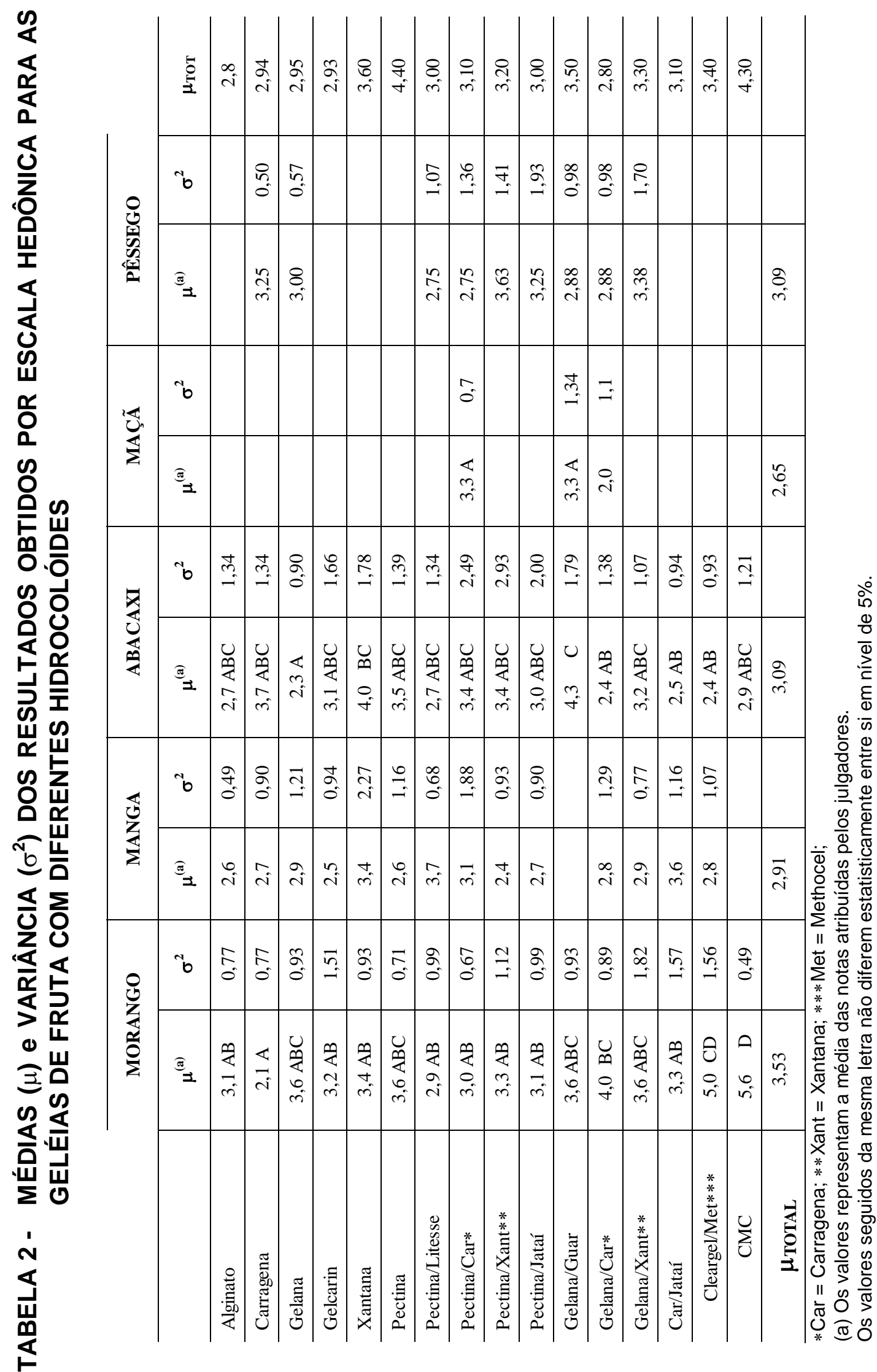




\section{FIGURA 6 - REPRESENTAÇÃO GRÁFICA DOS RESULTADOS MÉDIOS DE PREFERÊNCIA DE SABOR PARA AS GELÉIAS}

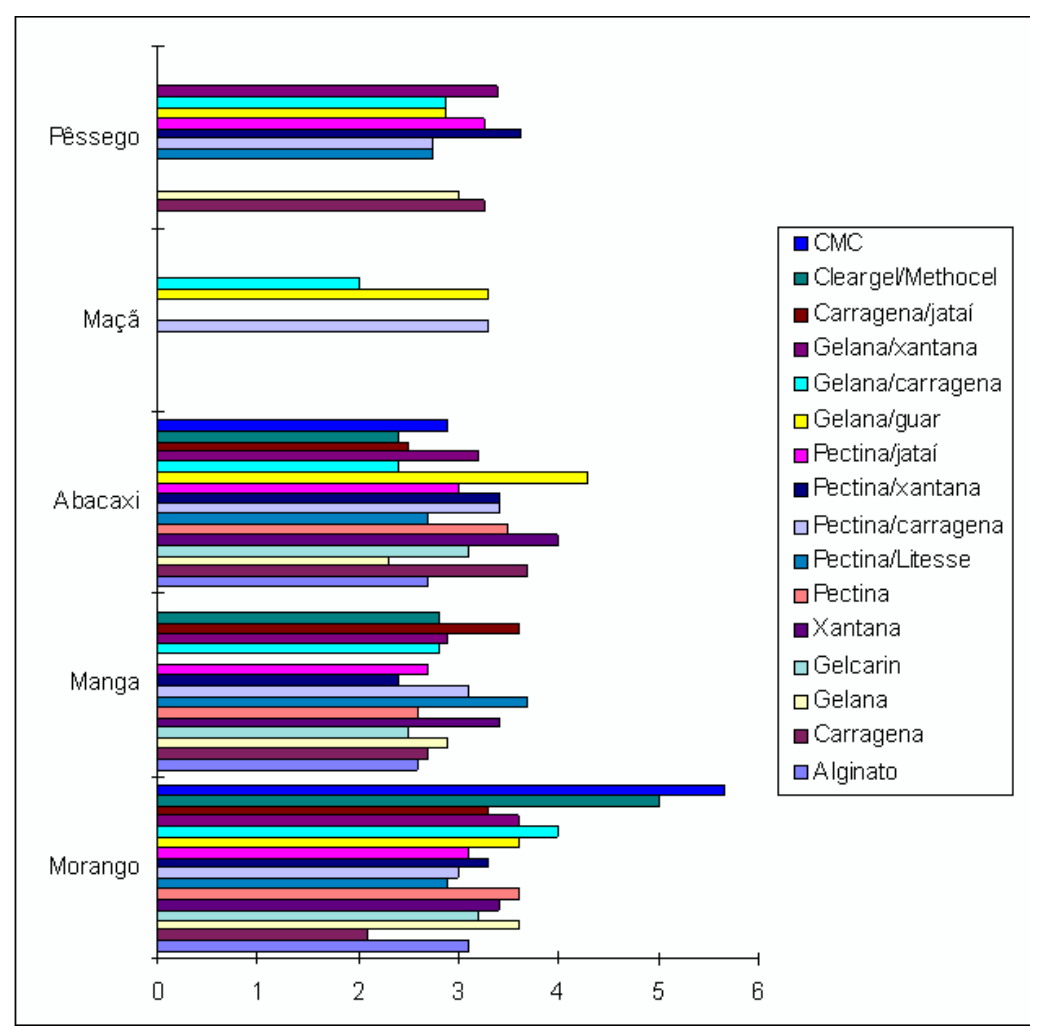

Não houve diferença significativa quanto ao sabor entre as geléias de manga, sendo as médias menos favoráveis obtidas pelas amostras com pectina/polidextrose, Cleargel/Methocel e Goma xantana e as melhores com pectina/goma jataí, Gelcarin e alginato.

A geléia de abacaxi com gelana foi considerada a melhor amostra quanto ao sabor, seguida pelas amostras com Cleargel/Methocel, gelana/ carragena e carragena/goma jataí, respectivamente. Tais geléias apresentaram diferença significativa ao nível de 5\% em relação a amostra com gelana/guar, considerada a de menor qualidade de sabor, seguida pelas amostras com xantana, carragena e pectina.

A geléia de maçã com gelana/carragena foi considerada a melhor amostra quanto ao sabor, apresentando diferença significativa ao nível de 5\% em relação as amostras com pectina/carragena e gelana/guar.

Não houve diferença significativa entre as geléias de pêssego, sendo as melhores médias obtidas pelas amostras com pectina/polidextrose, pectina/xantana e gelana/carragena. Verificou-se médias menos favoráveis para as geléias com pectina/jataí e carragena/jataí. 
Apesar das geléias da mesma fruta terem apresentado valores próximos de $\mathrm{pH}$ e sua doçura ter sido obtida por quantidade igual do mesmo adoçante (aspartame), comentários dos julgadores sobre diferenças de sabor quanto ao nível de doçura e acidez, poderiam indicar o surgimento sinergismo ou supressão, alterando a percepção do gosto doce e ácido das geléias. A comprovação ou não destes fatos foi avaliada de forma mais aprofundada pelas características gerais das geléias mediante Análise Descritiva Quantitativa (ADQ).

\subsection{PREPARO E TESTE DAS AVALIAÇÕES EM PÓ}

Comparando-se os dados reológicos das geléias de morango preparadas a partir das formulações em pó (Figura 7), com aquelas preparadas a partir da adequação dos resultados dos géis modelo, observou-se que em geral a viscosidade e a fluidez apresentaram dados mais elevados e a força de gel mais baixos. A utilização de outra remessa de morangos com características físico-químicas diferentes, principalmente em relação ao teor de cálcio livre da fruta (6,07 mg\%), poderia justificar as variações nos resultados reológicos. Tais variações permaneceram entretanto dentro de faixa tolerável, não interferindo no aspecto geral do produto e demonstrando a viabilidade do processo.

Analisando-se as fichas de avaliação do preparo das geléias pode-se constatar que o produto agradou a todos, principalmente quanto ao sabor, aparência e textura. A praticidade do preparo das geléias foi comprovada e as instruções consideradas claras. Houve pequena variação de opinião em relação a aceitação do produto no mercado, pois cerca de $30 \%$ dos informantes preferiria adquirir geléia pronta, ao invés de preparála. Em relação a este fato, deve-se considerar que o custo do produto, que não atinge $20 \%$ do preço da geléia comercializada pronta, dependendo do hidrocolóide e edulcorante utilizados, não foi divulgado.

\section{CONCLUSÃO}

Os valores de fluidez, viscosidade e força do gel demonstraram que a utilização de hidrocolóides isolados ou associados, como agentes geleificantes, ao invés de pectina BTM, permite implementação das propriedades reológicas.

As características reológicas dos hidrocolóides alteraram-se acentuadamente com a adição de fruta, sendo que os valores de viscosidade e força do gel aumentaram e os valores de fluidez diminuiram. Assim, as formulações deverão sofrer pequenas alterações em função da fruta empregada. 
FIGURA 7 - AVALIAÇÃO REOLÓGICA DAS GELÉIAS DE MORANGO
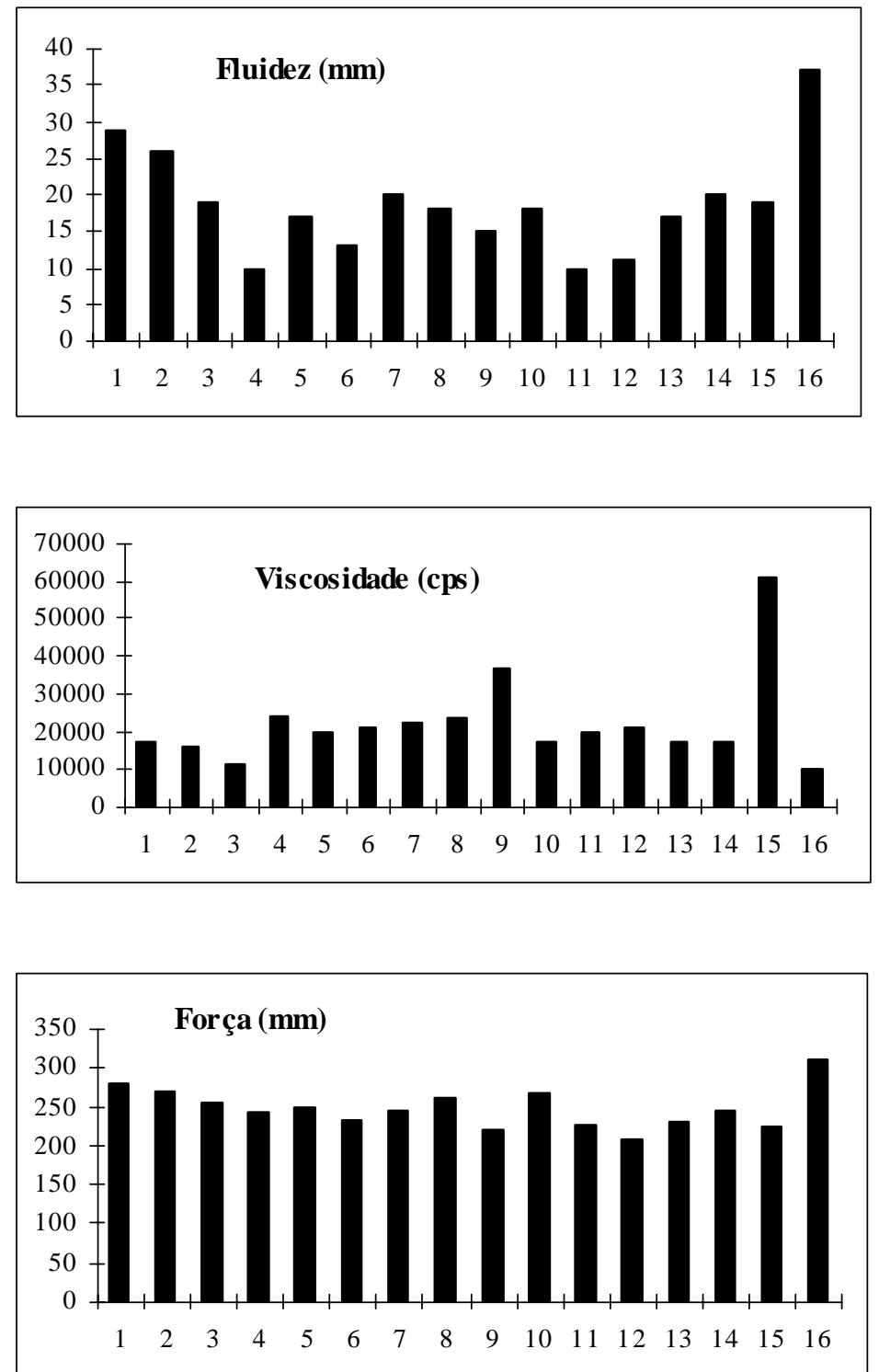

Alginato de Sódio (SBI)

Carragena (SBI)

Gelana (Kelco)

Gelcarin (FMC Corporation)

Goma xantana (SBI)

Pectina (Copenhagen Pectin)

Pectina (Copenhagen Pectin) \Litesse (Pfizer)

Pectina (Copenhagen Pectin) \Carragena (SBI)
Pectina (Copenhagen Pectin) \Goma xantana (SBI)

Pectina (Copenhagen Pectin) \Goma Jataí (SBI)

Gelana (Kelco) \Goma guar (FMC Corporation)

Gelana (Kelco) \Carragena (SBI)

Gelana (Kelco) \Goma xantana (SBI)

Carragena (SBI) \Goma Jataí (SBI)

Cleargel (National) $\backslash$ Methocel (Dow)

Carboximetilcelulose (Aqualon) 
A análise sensorial evidenciou que não houve diferença significativa quanto ao sabor entre as geléias de manga e pêssego.

As geléias de morango formuladas com carragena, pectinalpolidextrose, pectinalcarragena e alginato destacaram-se (nesta ordem) como preferidas em relação ao sabor, diferenciando-se significativamente das amostras com gelana/ carragena, Cleargel/ Methocel e carboximetilcelulose. Quanto a geléia de abacaxi, as formulações com gelana, Cleargel/Methocel, gelana/carragena e carragena/jataí foram as preferidas, diferenciando-se significativamente em relação a amostra com gelanalguar, seguida por xantana, carragena e pectina. A geléia de maçã com gelanalcarragena foi considerada a melhor quanto ao sabor, apresentando diferença significativa em relação as amostras com pectinalcarragena e gelanalguar.

No cômputo geral, as geléias de morango apresentaram as médias mais favoráveis, seguida das de pêssego, abacaxi, manga e maçã.

Os resultados obtidos demonstraram que as formulações em pó desenvolvidas neste trabalho com diferentes hidrocolóides e diferentes edulcorantes podem ser empregadas para preparo doméstico de geléias com baixo teor de sólidos solúveis. Desta forma as pessoas podem preparar sua própria geléia com adição apenas da fruta desejada, obtendo produto de baixíssimo custo e alta qualidade.

\section{ABSTRACT}

The subject of this issue was to develop formulations for home making of low sugar jams for diabetics, with different hydrocolloids and sugar substitutes. Twenty-two different hydrocolloids have been tested as well as six sweeteners. Model gels obtained from pectin, gums or from both in association, were previously rheologically evaluated for fluidity, viscosity, and gel strength, so as to obtain associations with better profile. Powder formulations for jams have been developed from sixteen selected model gels, tested with pineapple, strawberry, mango, peach and apple. The free calcium level of the fruits was evaluated by atomic absorption spectrometry. The jams were prepaired in open vessels in such way that the final concentration was 25 to $30 \%$ of soluble solids and $55 \%$ of fruit. The jams were submited to the same rheological evaluations as the gels. The jams sweetened with aspartame were sensorially evaluated by hedonic flavour scale. The domestic preparation of jams using the developed powder formulations has been tested by volunteers from Associação do Diabético Carente do Paraná. The fluidity, viscosity and gel strength values demonstrated that the use of hydrocolloids isolated or in association with low methoxyl pectin, which is generally used isolated in most of the industries, allows improvement of the rheological properties. The viability of jam preparation from powder formulation as well as the good quality of the final product regarding flavour, appearance and texture have been stablished. 


\section{REFERÊNCIAS BIBLIOGRÁFICAS}

1 CAMPOS, A.M. Efeito de adoçantes e edulcorantes na formulação de geléias de fruta com pectina amidada. Curitiba, 1993. 166 p. Dissertação (Mestrado em Tecnologia Química) Universidade Federal do Paraná.

2 CAMPOS, A.M., CÂNDIDO, L.M.B. Formulação e avaliação físicoquímica e reológica de geléias com baixo teor de sólidos solúveis com diferentes adoçantes e edulcorantes. Ciência e Tecnologia de Alimentos, Campinas, v. 15, n. 3, p. 268-278, dez. 1995.

3 CAMPOS, A.M., CÂNDIDO, L.M.B. Comportamento de géis de pectinas amidadas em presença de diferentes adoçantes e teores variados de cálcio. Boletim do Centro de Pesquisa e Processamento de Alimentos, Curitiba, v. 12, n. 1, p. 39-54, jan./jun. 1994.

4 CÂNDIDO, L.M.B., CAMPOS, A.M. Alimentos para fins especiais: dietéticos. São Paulo : Varela, 1996. 400 p.

5 COUTANT, A. Guar gum, locust bean gum and xanthan gum: functional agents for texture of food products. In: FOOD INGREDIENTS SOUTH AMERICA (São Paulo :1995). São Paulo : Rhodia/Rhone Poulenc Group, Sept. 12, 1995. 39 p.

6 DAMÁSIO, M. H., COSTELL, E., DURÁN, L. Influence of composition on non-oral texture of k-carragena, LBG, guar gum mixed gels. Food Quality and Preference, Reading, v. 5, p. 195-201, 1994.

7 DURÁN, L., COSTELL, E., IZQUIERDO, L. Effects of concentracion, $\mathrm{pH}$ and salt content on flow characteristics of xanthan gum solutions. Food Hydrocolloids, Oxford, v. 8, n. 3-4, p. 265-275, 1994.

8 DURÁN, L., COSTELL, E., IZQUIERDO, L. Low sugar bakery jams with gellan gum-guar gum mixtures. Influence of composition on texture. Food Hydrocolloids, Oxford, v. 8, n. 3-4, p. 373-381, 1994.

9 DZIEZAK, J.D. Ingredients for sweet success. Food Technology, Chicago, v. 43, n.10, p. 104-116, Oct. 1989.

10 DZIEZAK, J.D. A focus on gums. Food Technology, Chicago, v. 45, n. 3 , p. $116-133$, Mar. 1991. 
11 DZIEZAK, J.D. Gellan gum recieves FDA approval. Food

Technology, Chicago, v. 44, n. 11, p. 88-90, Nov. 1990.

12 FMC Corporation. Tecnologia geral de aplicação de carragena. Philadelphia : FMC Corporation, Food Ingredients Division, [198?], $31 \mathrm{p}$.

13 GENU handbook for the fruit processing industry. Lille skensved: the Copenhagen Pectin Factory Ltd., 1984. 139 p.

14 KELCOGEL. Gellan gum-multifuncional gelling agent. New Jersey : KELCO Division of Merck \& Co., 1992. $10 \mathrm{p}$.

15 KOKINI, J.L., SURMAV, K. Steady shear viscosity firet normal stress difference and recoverable strain in carboxymethylcellulose, sodium alginate and guar gum. Carbohydrate Polymers, New York, v. 23, p. 27-33, 1994.

16 MALKKI,Y., HEINIO, R. L., AUTIO, K. Influence of oat gum, guar gum and carboxymethylcellulose on the perception of sweetness and flavour. Food Hydrocolloids, Oxford, v. 6, n. 6, p. 525-532, 1993.

17 MODLISZEWSKI, J.J. Carragena (reprodução de demonstração técnica). Philadelphia : FMC Corporation, Food Ingredients Division, 1983. $12 \mathrm{p}$.

18 MIYOSHI, E., TAKAYA, T., NISHINARI, K. Gel-sol transition in gellan gum solutions. II DSC studies on the effects of salts. Food Hydrocolloids, Oxford, v. 8, n. 6, p. 529-542, Dec. 1994.

19 OKAMOTO, T, KUBOTA, K, KUWAHARA, N. Light scattering study of gellan gum. Food Hydrocolloids, Oxford, v. 7, n. 5, p. 363-371, 1993.

20 PRODUCT update. New ingredients and aplications. Food Technology, Chicago, v. 48, n. 1, p. 114-128, Jan. 1994.

21 SHIMASAKI, T., OGINO, K. Viscoelastic properties of gellan gum aqueous solutions. Food Hydrocolloids, Oxford, v. 7, n. 5, p. 417-426, Dec. 1993.

22 GUMS: the missing link. Food Engineering International, Radnor, v. 19, n. 3, p. 13-16, June, 1994. 